\title{
PREDICTING EPHEMERAL GULLY LOCATION AND LENGTH USING TOPOGRAPHIC INDEX MODELS
}

\author{
P. Daggupati, K. R. Douglas-Mankin, A. Y. Sheshukov
}

\begin{abstract}
Ephemeral gullies (EGs) are incised channels resulting from concentrated overland flow that often form in a similar location every year. These erosional features add to producers' management efforts and costs. Locating EGs and predicting their length is crucial for estimating sediment load and planning conservation strategies. Since topography plays an important role in the formation of EGs, this study investigated the prediction of EG location and length in two agricultural areas (S1 and S2) in two different physiographic regions using four topographic index models: compound topographic index (CTI), slope area (SA), wetness topographic index (WTI), and slope area power (SAP). The impacts of digital elevation model (DEM) resolution, agricultural land use mask data source, and topographic model critical thresholds were also evaluated. Automated geospatial models were developed to locate and derive EG length. Results show that the SA model predicted EG occurrence and length better than other models tested. The SA and CTI model predictions had similar patterns in terms of locating EG trajectory; however, the CTI model had greater discontinuity along the trajectory. The method developed to derive length in this study was sensitive to discontinuity, so the performance of the CTI model was poor. Finer-resolution DEMs $(2 \mathrm{~m})$ predicted EG location and lengths better than coarser-resolution DEMs (10 $\mathrm{m}$ or greater). Use of actual field-level reconnaissance data instead of NASS data for agricultural land use masking decreased false negative classification by $16 \%$ or more for all models. Detailed calibration of the SA model yielded different optimal thresholds for the two study regions: $T_{S A}=30$ for $S 1$ and $T_{S A}=50$ for $S 2$. Topographic index models were found to be useful in locating EGs and estimating expected lengths, but site-specific calibration of the topographic index model threshold was required, which might limit the general utility of these methods.
\end{abstract}

Keywords. Ephemeral gully, Modeling, Sediment, Topography.

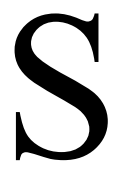
oil erosion by water in agricultural fields is a widespread land degradation problem (Montgomery, 2007) that occurs mainly through interrill and rill erosion, ephemeral gully (EG) erosion, and classical gully erosion. This study focuses on EG erosion, which is referred to as concentrated-flow erosion, mega-rill erosion, or shallow gully erosion. According to Foster (1986), EGs are larger than rills and smaller than classical gullies, and flow in EGs is clearly channelized.

Definitions of EGs vary. According to the Soil Science Society of America (SSSA, 2008), EGs are "small channels eroded by concentrated overland flow that can be easily filled by normal tillage, only to reform again in the same location by additional runoff events." Hauge (1977) and Poesen (1993) distinguished EGs from rills with a cross-

Submitted for review in December 2012 as manuscript number SW 10087; approved for publication by the Soil \& Water Division of ASABE in July 2013.

Contribution No. 13-189-J from the Kansas Agricultural Experiment Station, Manhattan, Kansas.

The authors are Prasad Daggupati, ASABE Member, Postdoctoral Research Associate, Spatial Science Laboratory, Texas A\&M University, College Station, Texas; Kyle R. Douglas-Mankin, ASABE Member, Professor, and Aleksey Y. Sheshukov, ASABE Member, Assistant Professor, Department of Biological and Agricultural Engineering, Kansas State University, Manhattan, Kansas. Corresponding author: Aleksey Sheshukov, 129 Seaton Hall, Kansas State University, Manhattan, KS 66506; phone: 785-532-5418; e-mail: ashesh@ksu.edu. sectional area of $930 \mathrm{~cm}^{2}\left(1 \mathrm{ft}^{2}\right)$ or greater. According to Grissinger (1996a, 1996b), EGs are produced by concentrated flow erosion in swales or other topographically controlled locations and may be either a continuous or discontinuous extension of a drainage network. Smith (1993) defined EGs as small drainage channels that, if not filled in, would become permanent features of the drainage network.

The importance of EG erosion is well established (Foster, 1986; Thorne et al., 1986; Poesen et al., 1996; Nachtergaele and Poesen, 1999; Poesen et al., 2003), but only a few process-based hydrologic or erosion models have included EG subroutines: Ephemeral Gully Erosion Model (EGEM; Woodward, 1999); Revised Ephemeral Gully Erosion Model (REGEM; Gordon et al., 2007); Chemicals, Runoff, and Erosion from Agricultural Management Systems (CREAMS; Knisel, 1980); Groundwater Loading Effects of Agricultural Management Systems (GLEAMS; Knisel, 1993); Water Erosion Prediction Project (WEPP; Flanagan and Nearing, 1995); and Annualized Agricultural Nonpoint Source Model (AnnAGNPS; Bingner and Theurer, 2003). These models, however, do not predict the location of EGs, which must be input into the models. A simple means of predicting the location of EG initiation is needed (Vandaele et al., 1996a; Vandekereckhove et al., 1998; Desmet and Govers, 1997; Knapen and Poesen, 2010). Souchere et al. (2003) reported that the development of models able to predict the location, 
length, and cross-sectional area of EGs is of great importance.

The concept of a topographic threshold is widely used to predict locations in the landscape where gullies may develop (Moore et al., 1988; Vandaele et al., 1996a; Vandekerckhove et al., 1998, 2000; Desmet et al., 1999; Knapen and Poesen, 2010; Poesen et al., 2011). The idea was first proposed by Horton (1945), who stated that a channel incision occurs when a threshold force is exceeded. Many studies used slope and drainage area to represent channel incision and found that an inverse relationship exists between drainage area and local slope that can be represented by a power-type equation (Patton and Schumm, 1975; Begin and Schumm, 1979; Vandaele et al., 1996a).

Another concept that is widely used to identify the location of EGs is unit stream power. The EG formation depends on "generation of concentrated surface runoff of sufficient magnitude and duration to initiate and maintain erosion, leading to channelization" (Thorne and Zevenbergen, 1984). Concentrated surface runoff can be represented by specific stream power, which is a function of discharge, slope, and channel width. Drainage area multiplied by slope yields a parameter that can be used to represent total stream power (Desmet et al., 1999).

The importance of topographic parameters such as slope and drainage area in locating EGs is well established. Another topographic parameter, plan curvature or convergence, also contributes to $\mathrm{EG}$ formation models because it provides the measure of the degree of flow convergence along the cross-section of a flow path (Zevenbergen and Thorne, 1987). Moore et al. (1991) indicated that slope $(S)$, upstream drainage area $(A)$, and plan curvature were primary topographic attributes that can be derived directly from digital elevation models (DEMs) and can be combined in some form (e.g., $S \cdot A$ or $\ln [A / \mathrm{S}]$ ) to characterize the spatial variability of specific processes occurring in the landscape; these combinations of primary topographic attributes are commonly referred to as topographic index models, topographic indices, secondary topographic attributes, compound attributes, or compound indices (Moore et al., 1991). In this study, the term "topographic index models" will be used to refer to models that represent combinations of primary topographic attributes.

Several topographic index models were studied in the past few decades to predict the location of EGs. Thorne et al. (1986) used the CTI (compound topographic index) model to predict EG formation:

$$
t_{\mathrm{CTI}}=S \cdot A \cdot \mathrm{PLANC}
$$

where $t_{\mathrm{CTI}}$ is a topographic EG index value, $S$ is local slope $\left(\mathrm{m} \mathrm{m}^{-1}\right), A$ is upstream drainage area $\left(\mathrm{m}^{2}\right)$, and PLANC is plan curvature $(\mathrm{m}$ per $100 \mathrm{~m})$. Formation of an EG occurs when $t$ exceeds some critical threshold value $(T)$. Parker et al. (2007) tested the CTI model to predict EG locations in a GIS environment for different sites and found that $T_{\mathrm{CTI}}$ varied from 5 to 62 depending on the study site, and that the general pattern of EGs predicted did not change when $T_{\text {CTI }}$ varied between 10 and 100 .
Moore et al. (1988) used two methods to estimate EG location: the SA (slope area index) model:

$$
t_{\mathrm{SA}}=S \cdot A_{S}
$$

and the WTI (wetness topographic index) model:

$$
t_{\mathrm{WTI}}=\ln \left(A_{S} / S\right)
$$

where $t_{\mathrm{SA}}$ and $t_{\mathrm{WTI}}$ are topographic EG index values, $S$ is slope gradient $\left(\mathrm{m} \mathrm{m}^{-1}\right)$, and $A_{s}$ is unit upstream drainage area $\left(\mathrm{m}^{2} \mathrm{~m}^{-1}\right)$. Moore et al. (1988) found that EGs were constrained to areas for which $S \cdot A_{S}>18$ (i.e., $T_{\mathrm{SA}}=18$ ) and $\ln \left(A_{S} / S\right)>6.8$ (i.e., $\left.T_{\text {WTI }}=6.8\right)$. Vandaele et al. (1996b) reported that the EG locations in a study area in south Portugal were better predicted using $T_{\mathrm{SA}}=40$ and $T_{\mathrm{WTI}}=$ 9.8 .

Vandaele et al. (1996a) used the SAP (slope area power index) model:

$$
t_{\mathrm{SAP}}=S \cdot A_{s}^{b}
$$

where $t_{\mathrm{SAP}}$ is a topographic EG index value, $S$ is slope gradient $\left(\mathrm{m} \mathrm{m}^{-1}\right), A_{s}$ is unit contributing area $\left(\mathrm{m}^{2} \mathrm{~m}^{-1}\right)$, and $b$ is an empirical coefficient commonly assumed to be 0.4 (Vandaele et al., 1996a, 1996b; Desmet et al., 1999). Vandaele et al. (1996a) tested the model in the Kinderveld catchment in Spain and found out that $T_{\mathrm{SAP}}=0.486$ was needed for locating initiation points of EGs. In separate studies, Desmet et al. (1999) reported that $T_{\mathrm{SAP}}=0.75$ and Vandaele et al. (1996b) reported that $T_{\mathrm{SAP}}=1.0$ performed better in predicting location of EGs in their study areas.

The topographic index models discussed above were used to locate the EGs. Although the importance of length is well established, none of these studies used these topographic index model results to derive EG length (Woodward, 1999; Nachtergaele et al., 2001a, 2001b; Capra et al., 2005, 2009; Gordon et al., 2007; Poesen et al., 2011). Length of an EG is an important parameter because it is needed as an input by process-based models, such as EGEM and WEPP, to estimate EG sediment losses (Woodward, 1999). Nachtergaele et al. (2001a, 2001b) reported a strong correlation between EG length and volume of soil eroded. Length of an EG also can be used to estimate EG volume using simple models (Capra et al., 2005, 2009; Poesen et al., 2011). Gordon et al. (2007) reported that topographic index models are used to locate potential EG locations, but no method is currently available to predict EG length.

The goal of this study was to evaluate existing topographic index models (CTI, SA, WTI, and SAP) in predicting EG location and length within agricultural fields according to two metrics: occurrence (presence or absence within a given area) and length (total accumulated length within a given area). Specific objectives were to (1) develop a GIS-based methodology to locate and derive length of EGs using existing topographic index models, (2) compare and evaluate the impacts of DEM resolution $(2 \mathrm{~m}, 10 \mathrm{~m}$, and $30 \mathrm{~m})$ and agricultural land use mask data source (NASS or field reconnaissance) on EG occurrence and length predictions, and (3) evaluate the impacts of topographic index model thresholds $(T)$ on EG occurrence and length predictions. 


\section{STUDY AREA}

Two study areas where EGs are a major concern were selected. Study area 1 (S1) is located in Douglas County in northeastern Kansas, and study area 2 (S2) is located in Reno County in south central Kansas (fig. 1). S1 has an area of 4,359 ha $(10,771 \mathrm{ac})$ (43\% cropland), and S2 encompasses 1,927 ha $(4,762$ ac) (81\% cropland). Grain sorghum and corn were the major crops in S1, and wheat was the major crop in S2. The EGs in S1 were smaller (mostly single EGs; average length: $210 \mathrm{~m}$ ) and narrower, whereas the EGs in S2 were larger (mostly branched EGs; average length: $408 \mathrm{~m}$ ) and wider. The average catchment in which EGs were present was 2.5 ha $(6.2 \mathrm{ac})$ with $1.7 \%$ slope in S1 and 2.35 ha $(5.8 \mathrm{ac})$ with $0.97 \%$ slope in S2. In this study, S1 was used for evaluating performance of all topographic models, whereas S2 was used for verification of the best model.

\section{Methods}

\section{Digitizing EGs In STUdy AREAS}

One or more EGs were seen in many agricultural fields across the study areas during field reconnaissance surveys in 2009, 2010, and 2011, especially after rain events
(Daggupati et al., 2010); however, field measurements of EG characteristics (e.g., length, width, and depth) were not possible because access to the agricultural fields (private land) in both study watersheds was limited. Because of this limitation, we drove on public roads in the study areas and recorded the fields that were observed to have EGs. During field reconnaissance, a common landuse unit (CLU) field boundary shapefile was edited in ArcGIS on a laptop computer to record fields with EGs.

In the lab, the shapefile of fields with EGs was overlaid on a corresponding aerial image. The 2010 National Agricultural Imagery Program aerial image was selected for S1, and the 2003 Digital Ortho Quarter Quadrangle aerial image was selected for S2 because EGs could be clearly identified on these images. Aerial images from other years (1995 through 2011) were also acquired, but locating EGs was difficult on these images since they were taken during the crop growing season when a crop canopy was fully established. EGs were manually digitized over the aerial images in the study areas in the fields where EGs were observed during field visits. Extreme care was taken to digitize the trajectory of each EG located on the aerial image. Starting and ending points of each EG were difficult to determine precisely. Color changes on an aerial image and our expert judgment were used to digitize accurately,

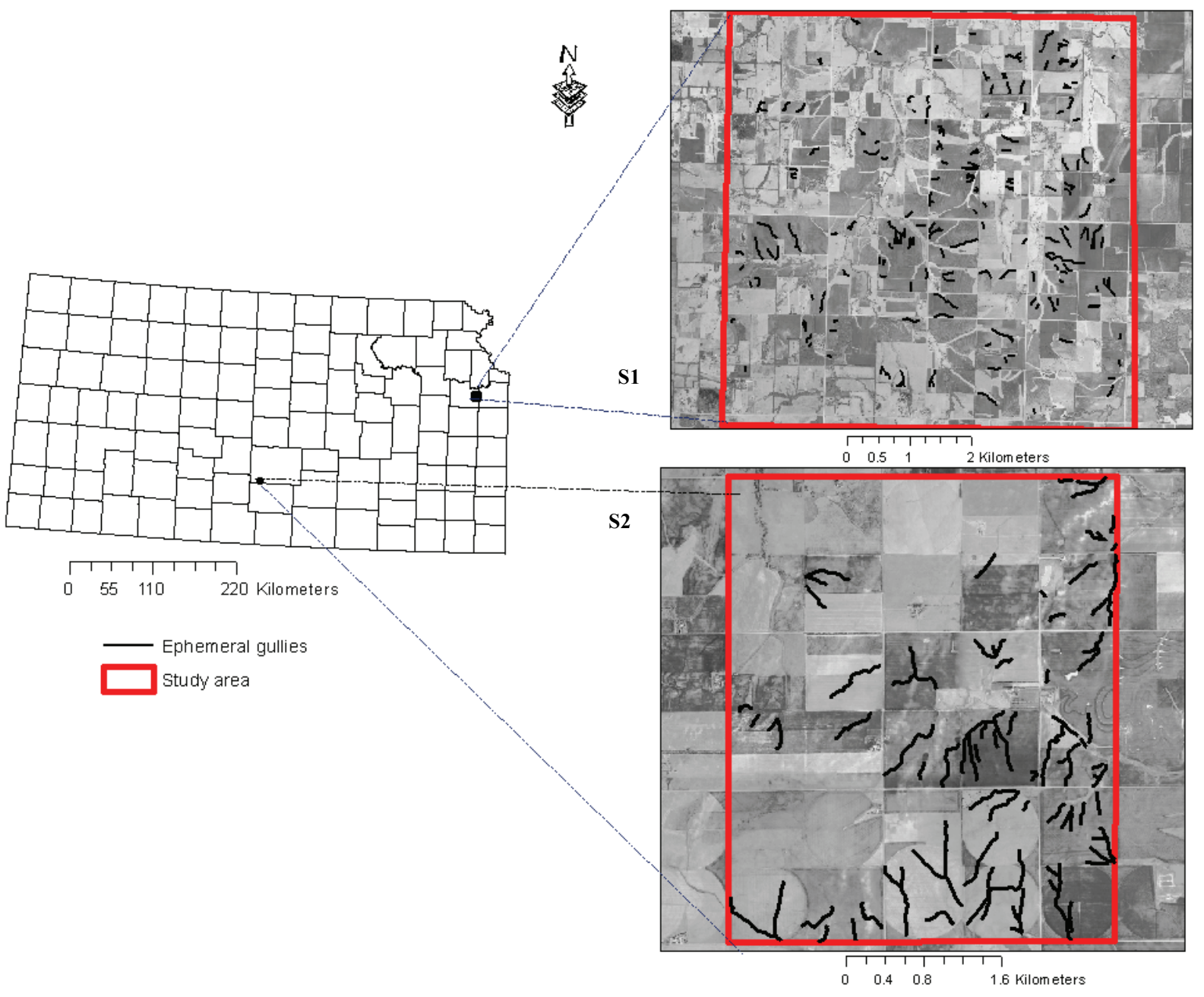

Figure 1. Study areas S1 and S2 showing digitized ephemeral gullies. 
Table 1. EG topographic index models and thresholds tested in S1.

\begin{tabular}{ccccc}
\hline Model & Equation & Eq. No. & Thresholds $(T)$ & References \\
\hline CTI & $t_{\mathrm{CTI}}=S \cdot A \cdot P L A N C$ & $(1)$ & 12,62 , and 100 & Thorne et al. (1986), Parker et al. (2007) \\
SA & $t_{\mathrm{SA}}=S \cdot A_{s}$ & $(2)$ & 5,18 , and 40 & Moore et al. (1988), Vandaele et al. (1996a) \\
WTI & $t_{\mathrm{WTI}}=\ln \left(A_{s} / S\right)$ & $(3)$ & $6.8,9.8$, and 12 & Moore et al. (1988), Vandaele et al. (1996b) \\
SAP & $t_{\mathrm{SAP}}=S \cdot A_{s}^{0.4}$ & $(4)$ & $0.3,0.5$, and 1 & Vandaele et al. (1996a, 1996b), Desmet et al. (1999) \\
\hline
\end{tabular}

with an estimated error of approximately $5 \%$ of EG length. Google Earth together with hill-shade images (which enhanced the relief of the surface) were used to verify and cross-check the location during the digitizing process. Many EGs (69\% in S1, 38\% in S2) were seen on the aerial image within the study area but were not visible from the windshield during the field visit for several reasons: (1) EGs were located far away from roads or obscured by topographic features, (2) established crops concealed the EGs during the field visit, or (3) multiple EGs were located within one field. EGs that were located on the aerial image but were not seen during the field visit were also digitized. Because this study compared model-simulated EGs to observed EGs (i.e., digitized EGs on the aerial image), including all EGs was considered essential. Finally, the digitized EGs were used as observed or reference data to evaluate performance of the topographic index models.

\section{EG TOPOGRAPHIC INDEX MODELS AND THRESHOLDS}

Four published EG topographic index models were used to predict EG location (table 1). EG topographic index models determine the presence or absence of an EG at each point (i.e., in a pixel) within a given area for which the topographic EG index value ( $t$ in eqs. 1 through 4 ) exceeds a threshold value $(T)$. For the CTI and SAP models, the three (minimum, middle, and maximum) values of $T$ were selected based on values reported in the literature $(12,62$, and 100 for the CTI model, and 0.3, 0.5, and 1 for the SAP model). For the SA model, the new value of 5 was added to widen the default reported range of 18 to 40 to seek better identification of EGs, whereas for the WTI model the maximum value was increased to 12 from the default range of 6.8 to 9.8 because no ephemeral gullies were recorded within that range.

\section{DATA INPUTS FOR TOPOGRAPHIC INDEX MODELS}

DEMs provide key data for topographic index models. Topographic attributes, such as slope, upstream drainage area, and plan curvature are directly derived from DEMs. Many studies have investigated the impact of DEM resolution for evaluating model responses to changes in topographic attributes and have concluded that DEM resolution substantially affects topographic attributes and thereby model results (Holmes et al., 2000; Chaubey et al., 2005; Parker et al., 2007; Momm et al., 2011). Impacts of DEM resolution $(2 \mathrm{~m}, 10 \mathrm{~m}$, and $30 \mathrm{~m})$ on the performance of topographic index models were evaluated in S1 to correctly predict EG location.

EGs within agricultural fields were of interest in this study; therefore, land use was used as an input to mask areas other than agricultural fields. Daggupati et al. (2011) reported that the land use data source has a major impact on modeling results for field-scale targeting, so this study evaluated the impacts on topographic index model performance of masking agricultural lands using either USDA National Agricultural Statistical Service (NASS) data or field reconnaissance land use data. Field reconnaissance land use data were collected during EG field reconnaissance in 2011, described above. Field boundaries used for both data sources were digitized manually using high-resolution aerial images. Care was taken to exclude waterways from the digitized land use.

\section{METHODOLOGY TO LoCATE EGS}

An automated geospatial model was built in a GIS environment (ESRI, 2011) using a model builder platform (Daggupati, 2012) to locate EGs for each of the topographic index models. The geospatial model requires elevation (DEM), land use, and roads as inputs. When the inputs are satisfied, the model calculates topographic attributes such as local slope, upstream drainage area, unit upstream drainage area, and plan curvature from the DEM. Filling a DEM or removing pits was not recommended by Kim (2007) and Bussen (2009) in gully-related studies because doing so fills out natural depressions that are important to EG formation; therefore, pit removal was not applied in this study. After the required topographic attributes are generated, the geospatial model calculates the topographic index value $(t)$ for each pixel in the study area and compares that value to the user-defined threshold $(T)$ for the topographic index model being used. If the pixel value of $t$ is greater than $T$, then an EG pixel is located on the output raster (fig. 2). Because our interest was in identifying EGs only in agricultural fields, the geospatial model used land use and roads to mask non-agricultural areas.

\section{Methodology to Estimate EG Length}

Several post-processing techniques were developed to derive length of EGs from the output raster (generated for each topographic index model from the geospatial model discussed above) using the following steps:

- Pixels that represent EGs in the output raster of a topographic index model were converted into a polyline shapefile (fig. 3a).

- The polylines within the trajectory of an EG were sometimes disconnected (fig. 3a) (i.e., some points along an apparent EG trajectory did not meet the given threshold). To make the polylines continuous within the trajectory of an EG, the polylines were "snapped" to each other using a snapping rule of $5 \mathrm{~m}$ (i.e., two lines that were $5 \mathrm{~m}$ apart, or less, were joined) (fig. 3b). Higher snapping distance $(>5 \mathrm{~m})$ resulted in lines snapping to other lines that were not part of the EG trajectory, thus distorting the shape along the trajectory (most prevalent in branched 


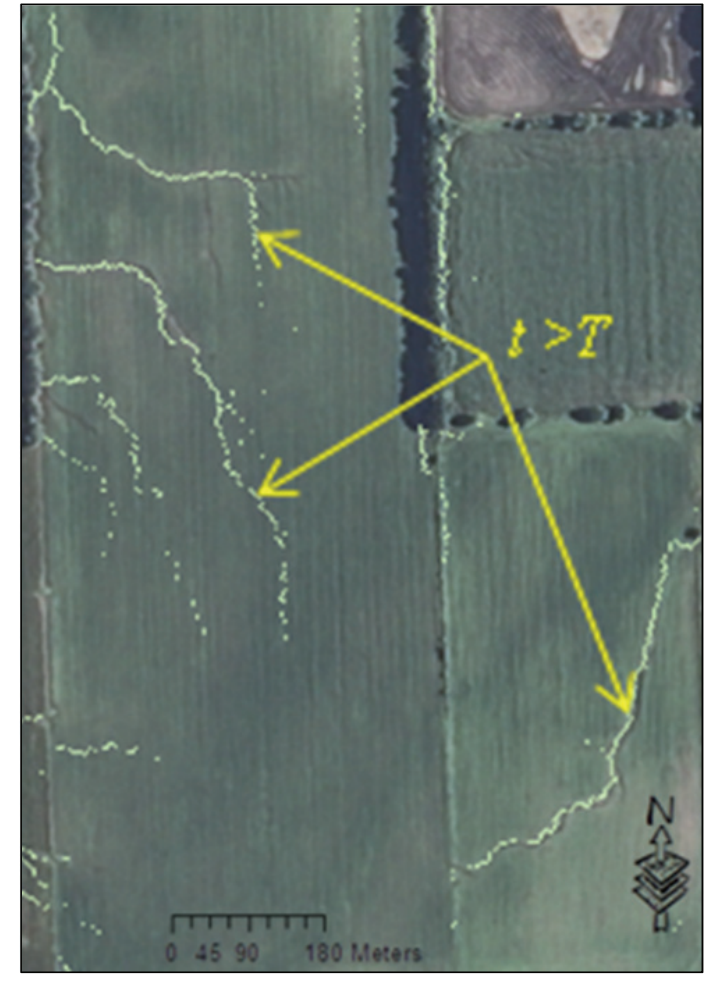

Figure 2. Ephemeral gully (EG) pixels in an agricultural field in study area $1(\mathrm{~S} 1)$.

EGs); consequently, snapping distance greater than $5 \mathrm{~m}$ was not used in this study.

- The lengths of the polylines were calculated, and lengths smaller than $10 \mathrm{~m}$ were removed (fig. 3c).

- At this point, each polyline had its own identification number, and many EGs were represented by multiple polylines. Catchments were developed separately using the DEM (areas outlined by blue lines in fig. 3d), and each individual polyline within a catchment was given a unique identification number (fig. 3d). The size of the catchment is user-defined and can be varied. In this study, 1 ha catchments were used. All individual polylines within a catchment were dissolved to a single polyline, which was considered an EG with a unique identification number.

- EGs shorter than $50 \mathrm{~m}$ were removed.

Using the above steps, EGs were given a length and a unique identification number so that they could be used either as input to the process-based model or to estimate soil loss volume using empirical relationships. It should be noted that lengths obtained by this method are "potential lengths" derived from topographic attributes and do not consider any processes occurring during the formation of EGs. It should also be noted that some discontinuity within lengths may remain along an EG trajectory. An automated geospatial model was developed in the ArcGIS environment using the model builder platform to automate the process of deriving lengths of EGs and eliminate the tedious steps outlined above.

\section{PeRformance OF TOPOGRAPHIC INDEX MODElS}

There is no established method to compare and evaluate the performance of topographic index models. Desmet et al. (1999) compared the percentage of predicted EG pixels that corresponded to the location of observed EG pixels. Parker et al. (2007) used visual interpretation by comparing potential EG pixels generated by the model to observed EG pixels.

Performance of each topographic index model to predict EG location and length was assessed by three methods: (1) visual evaluation of EG trajectories, (2) error matrix assessment of model performance in correctly identifying EG occurrence (presence or absence) within a given area, and (3) statistical assessment of model performance in correctly identifying EG length (total accumulated length) within a given area.

\section{Visual Evaluation}

Locations of EGs (model predictions along the trajectory) and derived lengths were evaluated using visual comparison of digitized EGs to model-simulated EG
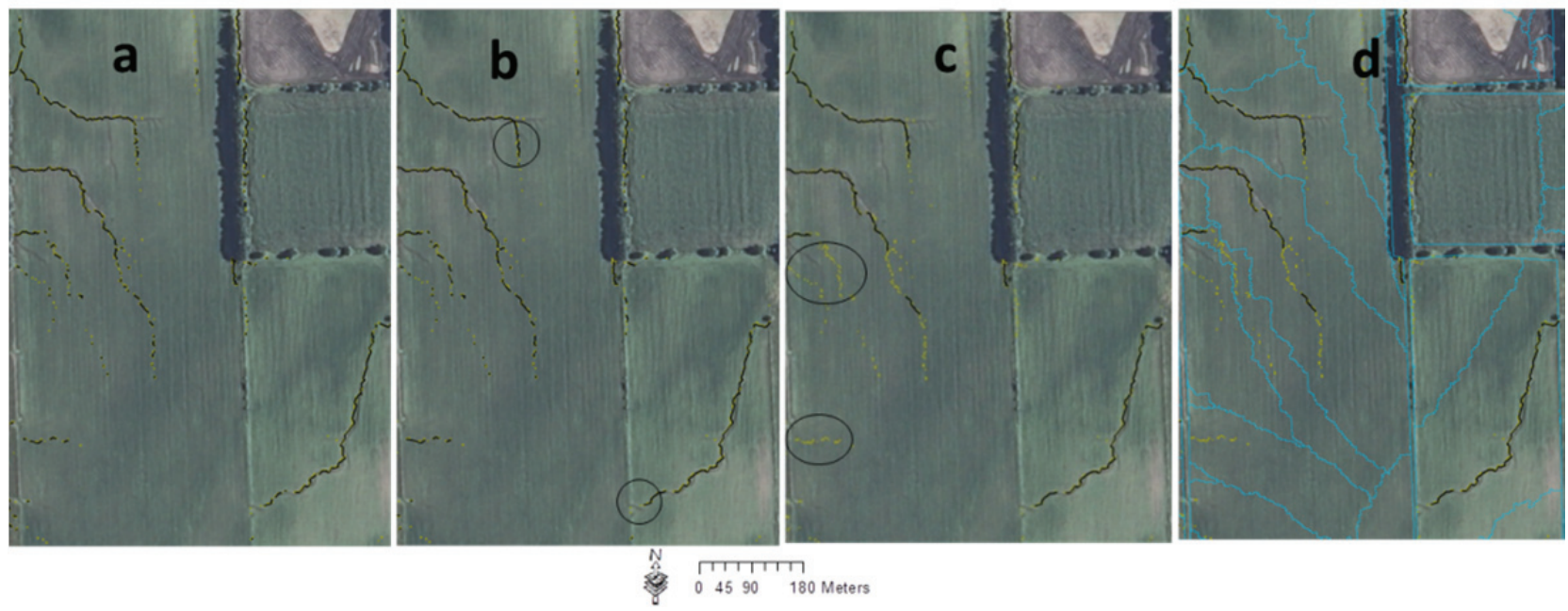

Figure 3. Steps in deriving the length of ephemeral gullies (EGs): (a) EG raster converted to polyline, (b) polylines snapped, (c) length of EGs calculated and smaller lengths $(<10 \mathrm{~m})$ deleted, and (d) EGs given unique identification number. Black polylines represent EGs, and polygons outlined by blue lines represent EG catchments. 
polylines. Visual evaluation provided a qualitative assessment of each model's performance.

\section{Occurrence Evaluation}

Statistical analysis using an error matrix approach was carried out to evaluate the occurrence (presence or absence) of EGs in a given area. An error matrix (also called confusion matrix, correlation matrix, or covariance matrix) summarizes the relationship between two datasets, often an observed dataset and a predicted dataset. The error matrix approach was used by Gutierrez et al. (2009) and Meyer and Martinez-Casasnovas (1999) to predict the location of gullies in rangeland for models developed by regression analysis using observed gully data.

In this study, we used the presence-absence model of the error matrix (table 2). One-hectare catchments within agricultural fields were used. Occurrence of an EG within a catchment was treated as a binary variable $(1=$ presence, and $0=$ absence) for each catchment based on predicted and observed EGs present within that catchment. The observed EGs are the digitized EGs over an aerial image based on the field reconnaissance survey, and the predicted EGs are the EGs generated by each of the topographic index models. Finally, the error matrix recorded the frequencies of the four possible types of prediction from analysis of the predicted and observed EGs for each catchment (table 2). Frequencies were recorded in an error matrix using the format in table 2 for each topographic index model. All the processes discussed above were automated using a geospatial model in the GIS environment (ArcGIS v. 10) using the model builder platform and an output of error matrix table generated in Excel format.

Several statistics can be calculated using the error matrix table (Daggupati, 2012). In this study, false positive rate, false negative rate, and kappa ( $\kappa)$ statistics (an occurrence statistic that measures the relationship between beyond chance agreement and expected disagreement) were used to evaluate the topographic index model performance (Congalton, 1991). A good model should have high $\kappa$ with low false positive and low false negative rates. A higher false positive rate does not necessarily indicate model error because the model may identify areas or catchments with high vulnerability to ephemeral gullying that had not yet developed EGs at the time of field reconnaissance or aerial imagery; however, high false negative rates are considered an error in model performance (Gutierrez et al., 2009).

Table 2. Error matrix to evaluate occurrence (presence or absence) of ephemeral gullies (EGs) in a catchment. ${ }^{[a]}$

\begin{tabular}{cccc}
\hline & \multicolumn{2}{c}{ Observed } & \\
\cline { 2 - 4 } Predicted & Present & Absent & Totals \\
\hline Present & $a$ (true positive) & $b$ (false positive) & $a+b$ \\
Absent & $c$ (false negative) & $d$ (true negative) & $c+d$ \\
\hline Totals & $a+c$ & $b+d$ & $N$ \\
\hline a] & $N=$ total number of catchments, $a=$ number of catchments with both \\
observed and predicted EGs present, $b=$ number of catchments with \\
predicted EGs present and observed EGs absent, $c=$ number of \\
catchments with observed EGs present and predicted EGs absent, and \\
$d=$ number of catchments with both observed and predicted EGs \\
absent.
\end{tabular}

\section{Length Evaluation}

There is no standard procedure to evaluate the EG length derived from topographic index models. In this study, we compared the total cumulative predicted length of EGs generated by the topographic index model to that of the observed EG length (digitized over aerial images) in each catchment for which both predicted and observed EGs were present ( $a$ in table 2). Statistics used for comparison were the coefficient of determination $\left(\mathrm{R}^{2}\right)$, Nash-Sutcliffe efficiency (NSE), and estimation bias (PBIAS). The above statistics are often used to evaluate the performance of watershed models (such as SWAT, AnnAGNPS, etc.) relative to measured data (Moriasi et al., 2007). Both NSE and $\mathrm{R}^{2}$ increase with improving model performance, with a value of 1 indicating perfect agreement between predicted and observed EG lengths. The optimal value of PBIAS is 0 , with low-magnitude values indicating accurate model predictions. Positive values indicate model underestimation bias, and negative values indicate model overestimation bias.

Each topographic index model along with a corresponding $T$ (table 1) was evaluated using the abovementioned location, occurrence, and length evaluation procedures in S1. DEM resolution $(2 \mathrm{~m}, 10 \mathrm{~m}$, and $30 \mathrm{~m}$ ) was compared and evaluated using all topographic index models. Agricultural land use mask data source (NASS or field) was compared and evaluated using the CTI and SA models. The best topographic index model, DEM resolution, and land use mask data source were selected and further evaluated using a range of $T$ values in $\mathrm{S} 1$ to understand how $T$ affected the topographic index model performance in predicting occurrences and lengths of EGs. Furthermore, the best topographic index model was applied in S2 under varying $T$ conditions to evaluate how $T$ affected topographic index model performance in a different geographic location.

\section{RESULTS AND DISCUSSION VISUAL INTERPRETATION OF LOCATION AND LENGTHS OF EGS}

Figure 4 shows output maps of location and derived lengths for the CTI (eq. 1, $T_{\mathrm{CTI}}=62$ ), $\mathrm{SA}$ (eq. 2, $T_{\mathrm{SA}}=18$ ), WTI (eq. 3, $T_{\mathrm{WTI}}=12$ ), and SAP (eq. $4, T_{\mathrm{SAP}}=0.3$ ) models using the given thresholds ( $T$ value noted for each equation), with $2 \mathrm{~m} \mathrm{DEM}$ and land use determined by field reconnaissance. The $T$ values used in the four models in figure 4 were selected based on their better prediction of EG location and length when compared with the results obtained with the two other values of $T$ within their respective models. The visual interpretations of the output maps showed that the CTI and SA models predicted EG locations (in the form of pixels along the trajectory of the observed EGs) better than the WTI and SAP models (left images of figs. 4b, 4c, 4d, and 4e) for given $T$ values.

The CTI and SA models had similar patterns in predicting location because both models are strongly influenced by slope and upstream drainage area, and a strong positive correlation exists between upstream 


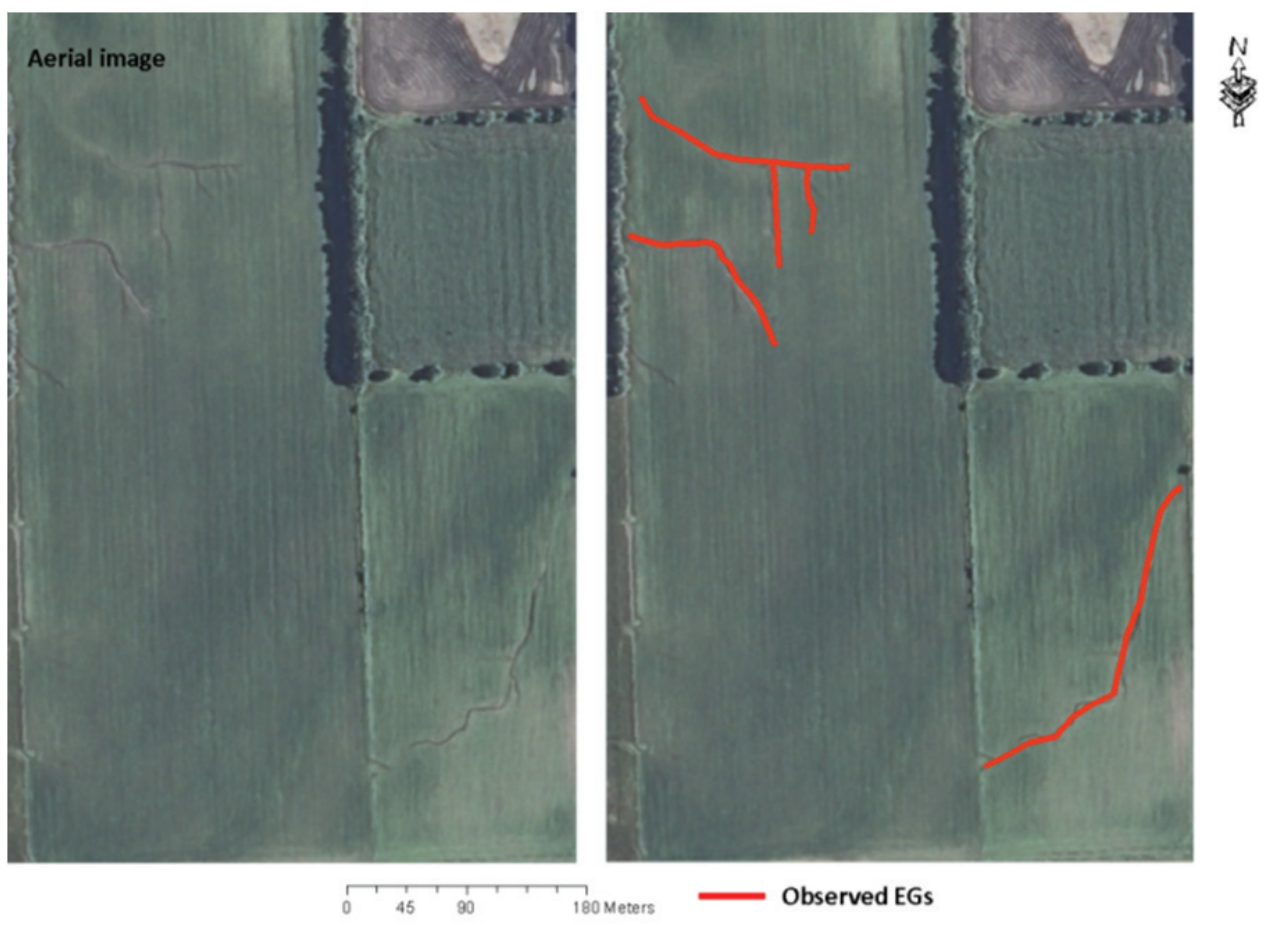

Figure 4a. Aerial image (left) and digitized EGs (right) of an agricultural field in study area 1 (S1).
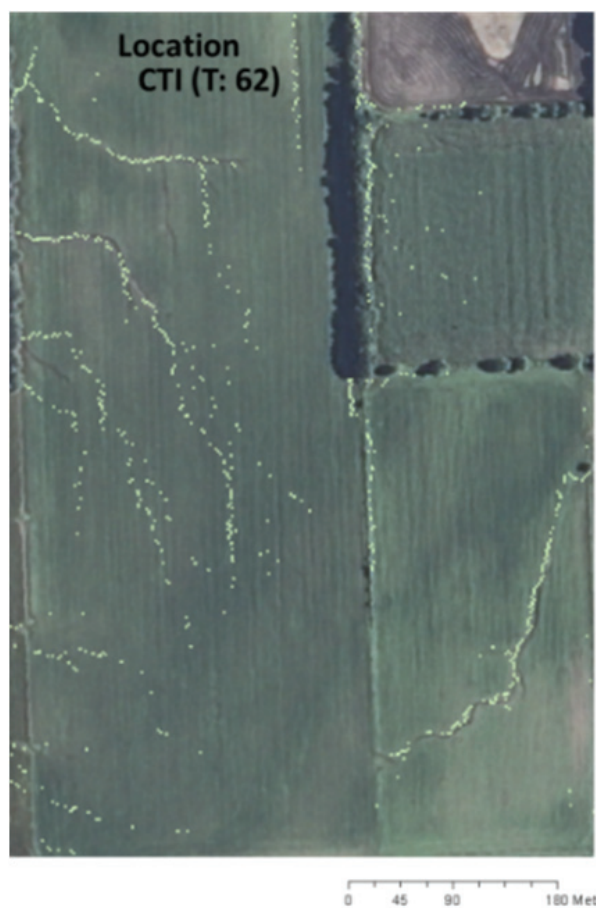

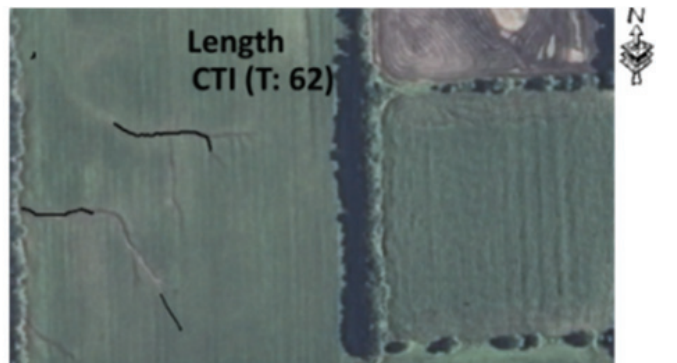

Figure 4b. Output maps of location (left) and derived lengths (right) for the CTI model (eq. 1, $T_{\mathrm{CTI}}=62$ ) in S1.

drainage area and plan curvature (which was included only in CTI). Closer observations, however, revealed that the CTI model predictions were more discontinuous along the trajectory (fig. 5). Discontinuity using the CTI model was due to the inclusion of plan curvature, which identifies the areas of reduced flow convergence in the landform topography and removes those pixels from the model predictions (Parker et al., 2007).

The WTI model was not able to predict the location of EGs in our study area using $T_{\mathrm{WTI}}=6.8$ and 9.8 , although these thresholds successfully predicted EG location in Portugal and Australia (Vandaele et al., 1996b; Moore et al., 1988). Increasing the $T_{\mathrm{WTI}}$ to 12 improved prediction of EG locations. Momm et al. (2011) also used $T_{\mathrm{WTI}}=12$ to locate EGs in a small field in Kansas; however, $T_{\mathrm{WTI}}=12$ tended to overpredict the location of EGs in this study. Increasing $T_{\text {WTI }}$ beyond 12 may have further improved model performance, but such simulations were not pursued in this study.

The SAP model underpredicted the location of EGs for 


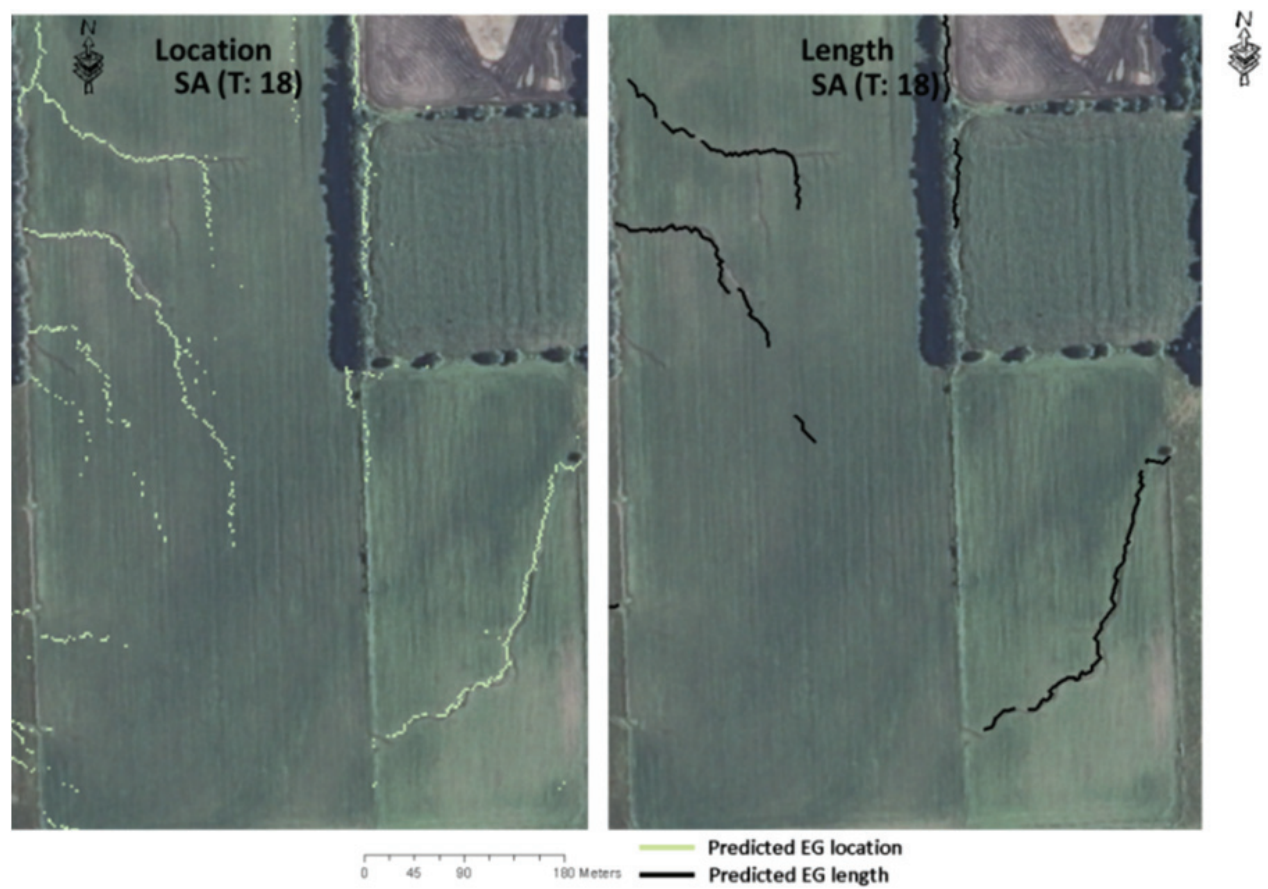

Figure 4c. Output maps of location (left) and derived lengths (right) for the SA model (eq. 2, $T_{\mathrm{SA}}=18$ ) in S1.

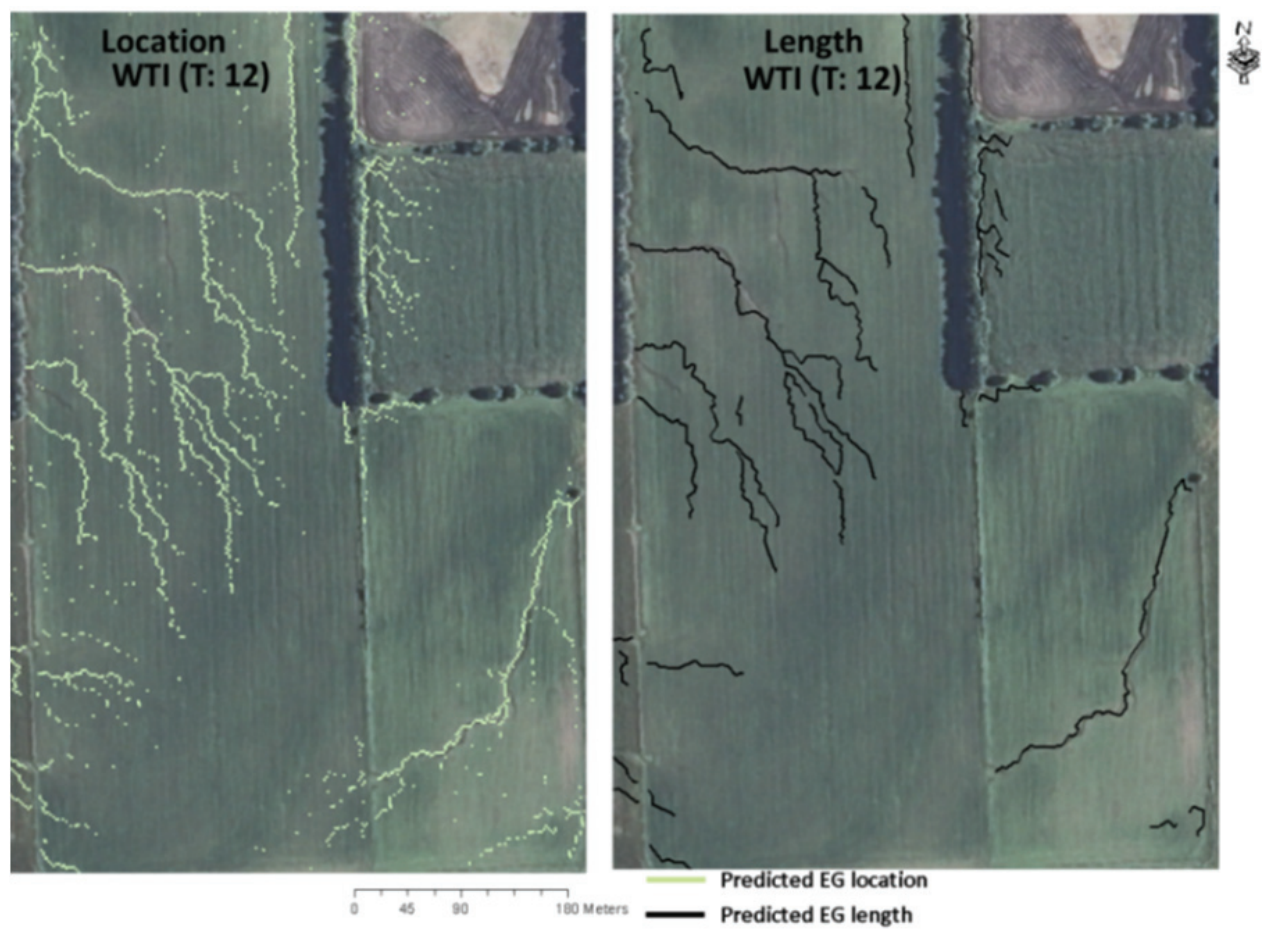

Figure 4d. Output maps of location (left) and derived lengths (right) for the WTI model (eq. 3, $T_{\text {WTI }}=12$ ) in S1.

all $T_{\mathrm{SAP}}$ values tested. Desmet et al. (1999) reported that lower values of $b$ in the SAP model (eq. 4) better predicted EG initiation points. In our study, we used $b=0.4$ in the SAP model, which may have contributed to this poor performance. Overall, the SA (eq. 2) model location predictions appeared better than those of the other topographic index models based on visual assessment of results.

The right images of figures $4 \mathrm{~b}, 4 \mathrm{c}, 4 \mathrm{~d}$, and $4 \mathrm{e}$ show the lengths derived from the location predictions for each topographic index model for selected $T$ values. Visual interpretations revealed that the WTI (eq. 3) and SAP (eq. 4) models were unable to predict length correctly along the EG trajectory. The CTI (eq. 1) model also was unable to predict the length due to its greater discontinuity of pixels along the trajectory (fig. 5), despite the methodology developed in this study that overcame small discontinuities by snapping together EGs separated by $5 \mathrm{~m}$ or less. 


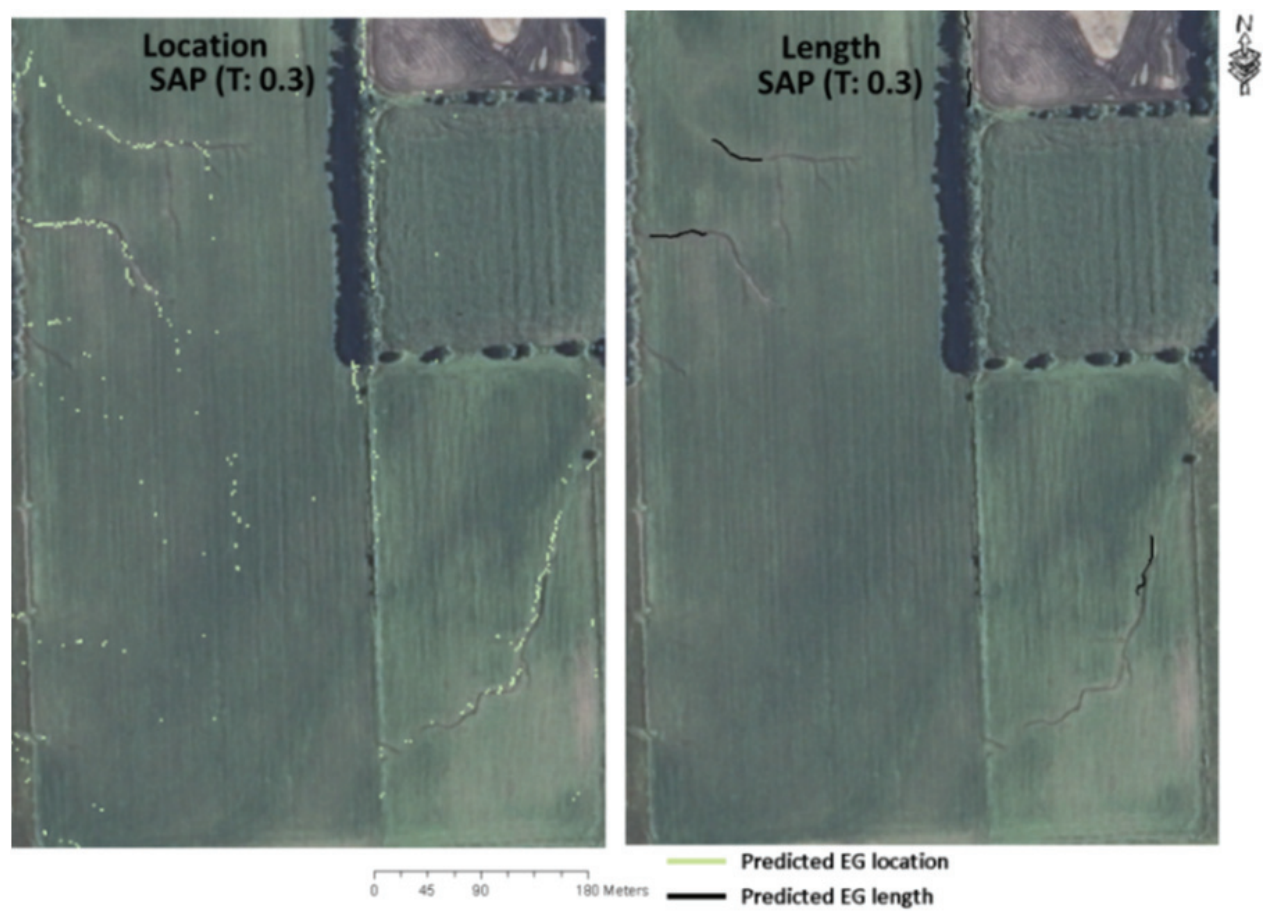

Figure 4e. Output maps of location (left) and derived lengths (right) for the SAP model (eq. $4, T_{\mathrm{SAP}}=0.3$ ) in S1.
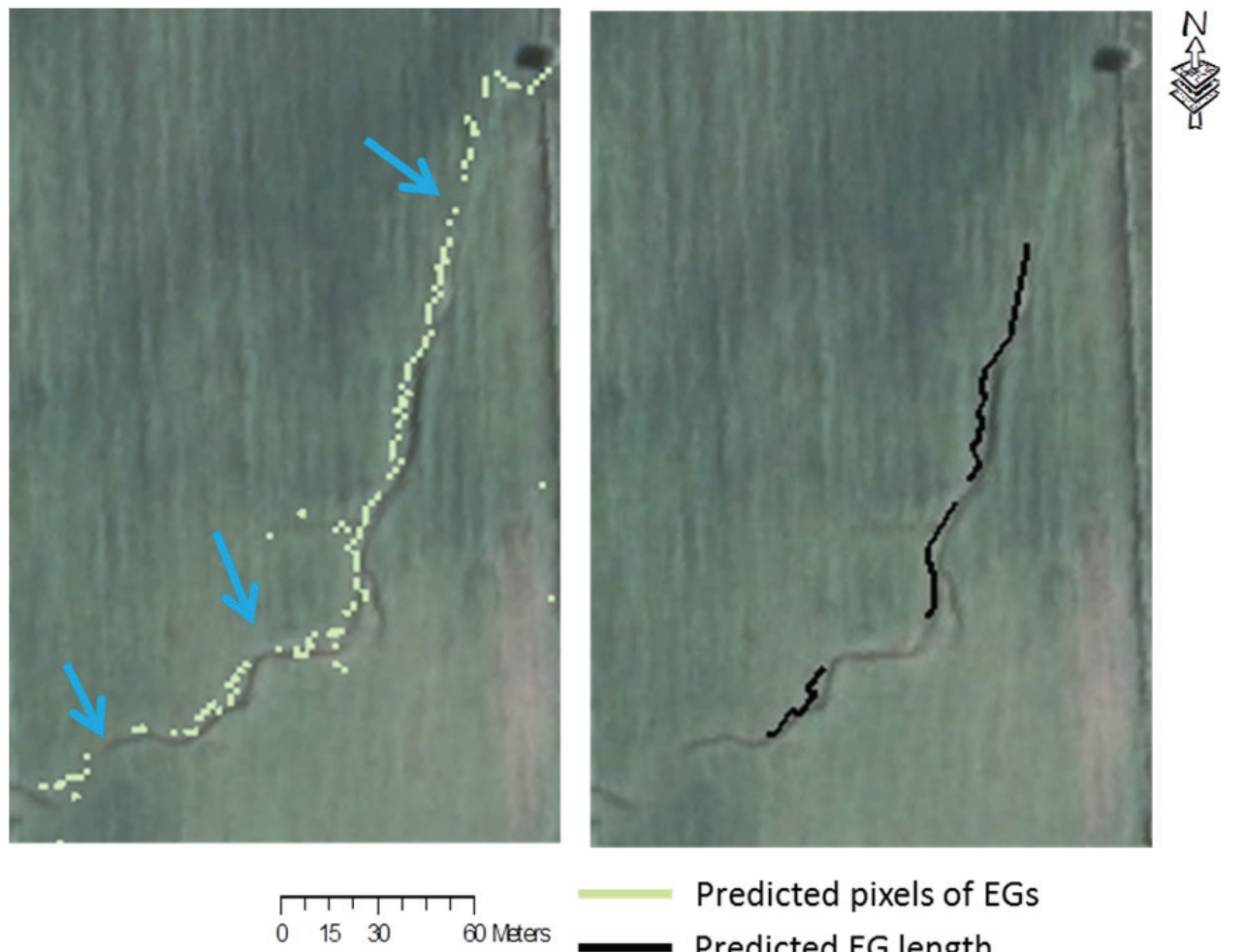

\section{Predicted pixels of EGs}

Predicted EG length

Figure 5. Closer observation of CTI model along the trajectory of EG (right). Light blue arrows (left) show discontinuity along the trajectory of the EG.

\section{OCCURRENCE ANalysis USING ERror Matrix}

Error matrix tables were developed (table 2), and statistics for the false positive rate and false negative rate (table 3) were used to analyze the performance of each topographic index model and their corresponding $T$ values, DEM resolutions, and land use data sources in S1. An important application of an EG model is to help watershed planners locate fields with greater potential for EG formation. With this goal in mind, our judgment was that it would be better to simulate the presence of an EG that, upon field inspection, was not there (i.e., a false positive) than to fail to simulate the presence of an EG that was there 
Table 3. Occurrence statistics for four topographic index models (SA CTI, SAP, and WTI) by topographic data resolution $(2 \mathrm{~m}, 10 \mathrm{~m}$, or $30 \mathrm{~m}$ ) and agricultural land use mask data (field or NASS).

\begin{tabular}{|c|c|c|c|c|c|}
\hline \multirow[b]{2}{*}{$T$} & \multirow[b]{2}{*}{ Statistic } & \multicolumn{2}{|c|}{$2 \mathrm{~m}$} & \multirow{2}{*}{$\begin{array}{c}10 \mathrm{~m} \\
\text { Field } \\
(\%)\end{array}$} & \multirow{2}{*}{$\begin{array}{c}30 \mathrm{~m} \\
\text { Field } \\
(\%)\end{array}$} \\
\hline & & $\begin{array}{c}\text { Field } \\
(\%)\end{array}$ & $\begin{array}{c}\text { NASS } \\
(\%)\end{array}$ & & \\
\hline \multicolumn{6}{|l|}{$\overline{\text { SA model }}$} \\
\hline \multirow[t]{2}{*}{5} & False positive rate & 54 & 52 & 25 & 1 \\
\hline & False negative rate & 21 & 27 & 37 & 97 \\
\hline \multirow[t]{2}{*}{18} & False positive rate & 27 & 25 & 8 & - \\
\hline & False negative rate & 21 & 37 & 66 & - \\
\hline \multirow[t]{2}{*}{40} & False positive rate & 10 & 10 & 3 & - \\
\hline & False negative rate & 38 & 43 & 83 & - \\
\hline \multicolumn{6}{|c|}{ CTI model } \\
\hline \multirow[t]{2}{*}{12} & False positive rate & 35 & 30 & 7 & 0 \\
\hline & False negative rate & 18 & 36 & 65 & 98 \\
\hline \multirow[t]{2}{*}{62} & False positive rate & 9 & 9 & 2 & - \\
\hline & False negative rate & 32 & 47 & 95 & - \\
\hline \multirow[t]{2}{*}{100} & False positive rate & 5 & 6 & 1 & - \\
\hline & False negative rate & 51 & 62 & 95 & - \\
\hline \multicolumn{6}{|c|}{ SAP model } \\
\hline \multirow[t]{2}{*}{0.3} & False positive rate & 7 & - & 6 & 0 \\
\hline & False negative rate & 49 & - & 83 & 100 \\
\hline \multirow[t]{2}{*}{0.5} & False positive rate & 1 & - & 1 & - \\
\hline & False negative rate & 86 & - & 96 & - \\
\hline \multirow[t]{2}{*}{1.0} & False positive rate & 0 & - & 0 & - \\
\hline & False negative rate & 98 & - & 100 & - \\
\hline \multicolumn{6}{|c|}{ WTI model } \\
\hline \multirow[t]{2}{*}{6.8} & False positive rate & - & - & - & - \\
\hline & False negative rate & - & - & - & - \\
\hline \multirow[t]{2}{*}{9.8} & False positive rate & - & - & - & - \\
\hline & False negative rate & - & - & - & - \\
\hline \multirow[t]{2}{*}{12.0} & False positive rate & 34 & - & 10 & 5 \\
\hline & False negative rate & 23 & - & 60 & 80 \\
\hline
\end{tabular}

(i.e., false negative). Thus, we generally attempted to minimize the false negative rate to a greater extent than the false positive rate.

\section{Impacts of DEM Resolution}

An ideal model would minimize both false negatives and false positives. The four topographic index models in this study exhibited a trade-off in which finer DEM resolution decreased false negatives but increased false positives. This trade-off is shown in figure 6; fewer potential EG pixels are observed as DEM resolution becomes coarser (from $2 \mathrm{~m}$ to $30 \mathrm{~m}$ ). Analysis of the error matrix indicates that as DEM resolution became coarser, from $2 \mathrm{~m}$ to $30 \mathrm{~m}$, the false negative rate increased, whereas the false positive rate decreased for all four models (table 3). For example, in the SA model with $T_{\mathrm{SA}}=5$, the false negative rate increased from $21 \%$ to $97 \%$, whereas the false positive rate decreased from $54 \%$ to $1 \%$ (table 3). As discussed above, the decrease in false negative rates for $2 \mathrm{~m}$ DEM resolution (relative to $10 \mathrm{~m}$ and $30 \mathrm{~m} \mathrm{DEM}$ ) was considered more beneficial than the decrease in false positive rates for the coarser $(10 \mathrm{~m}$ and $30 \mathrm{~m})$ DEM resolutions.

\section{Impact of Land Use}

The false positive rate either decreased slightly or remained the same, and the false negative rate increased as the land use mask changed from field to NASS in the CTI and SA models for all $T$ values. The increase in false negatives was attributed to misclassification of cropland fields as rangeland by NASS. This misclassification had the effect of removing some cropland fields from the analysis in the masking process. Because of this error, the EGs were not included in the analysis and thus not predicted by the model, despite the presence of observed EGs, thereby slightly increasing false negative rates.

The relatively small change in false positive rates between the field and NASS land use masks indicated a relatively small contribution of two potential sources of error. First, pixels representing rangeland in the middle of agricultural fields were resampled with surrounding majority pixels during GIS rectification of the NASS land use data. Second, the NASS land use mask led to prediction of EGs in waterways and forested areas on the edges of agricultural fields. Unless these areas are masked and
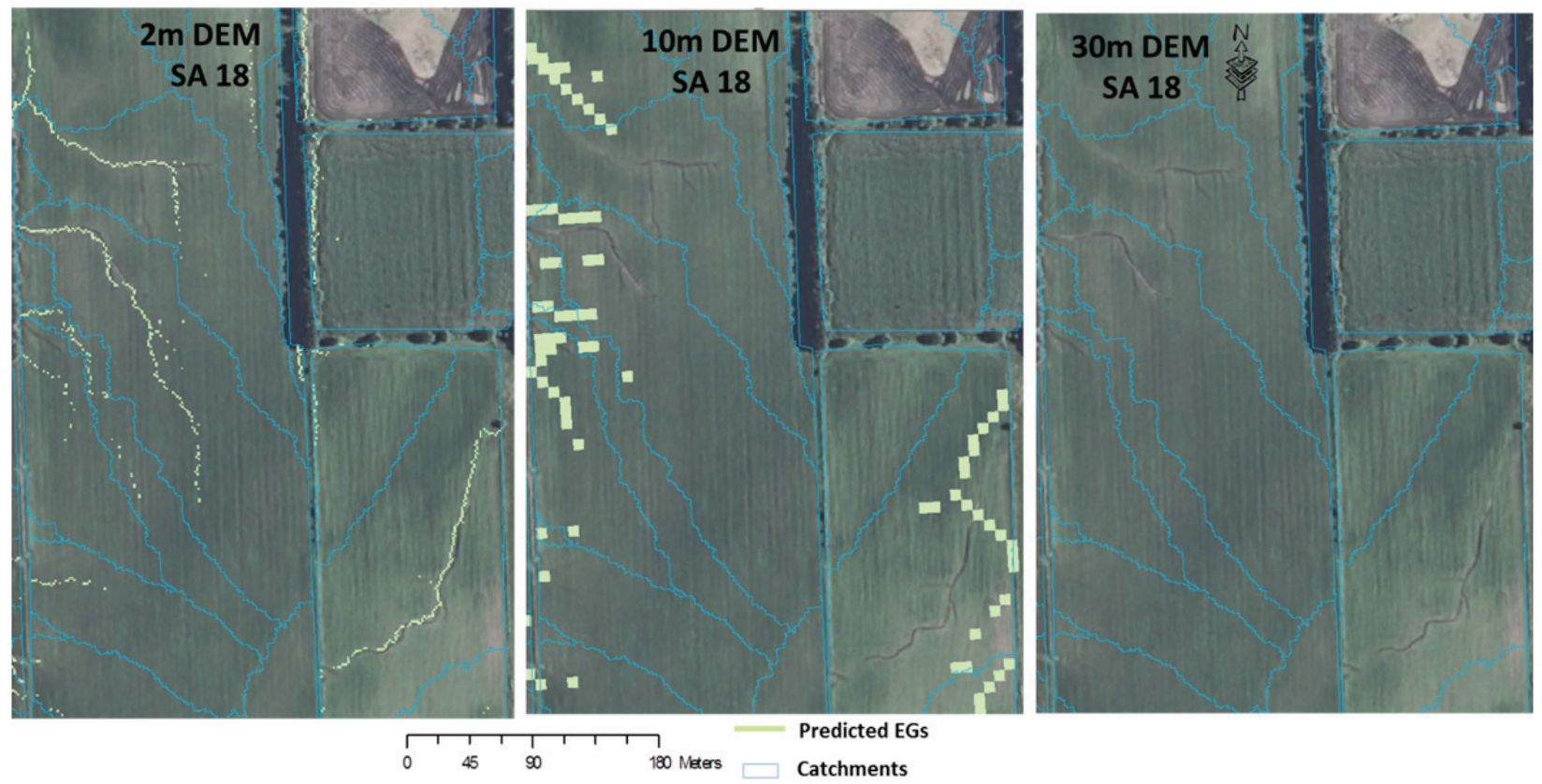

Figure 6. EG occurrence comparison for $2 \mathrm{~m}, 10 \mathrm{~m}$, and $30 \mathrm{~m}$ DEM resolutions at $T_{\mathrm{SA}}=18$. 
excluded from analysis, the topographic index models will predict the presence of EGs when they are not actually present (e.g., in waterways), increasing the false positives. Our definition of EG catchments as contained fully within cropland fields (i.e., catchments were clipped to field land use, so grassed waterways, forested lands, etc., were not included) minimized the impact of within-field resampling but could not compensate for NASS-misclassified edge-offield areas. However, similar false positive rates among the NASS and field land use data sources indicate that these errors were relatively small in the study areas.

\section{Impact of Thresholds}

All four topographic index models demonstrated an increasing false negative rate and decreasing false positive rate as $T$ value increased (table 3 ); for example, as $T_{\mathrm{SA}}$ increased from 5 to 40 using field land use and $2 \mathrm{~m}$ DEM resolution, the false positive rate decreased from $54 \%$ to $10 \%$ and the false negative rate increased from $21 \%$ to $38 \%$ (table 3). Better (lower) false positive and false negative rates were seen for $T_{\mathrm{SA}}=18$. Further investigation of the role of thresholds in correctly predicting the occurrence and length of EGs using the SA model is discussed below. Similar trends were observed in the case of the CTI model, where the false positive rate decreased and the false negative rate increased as $T_{\mathrm{CTI}}$ increased from 12 to 100 . Optimum false positive and false negative rates were not found with the selected thresholds in case of CTI. The CTI model also resulted in higher false negative rates because it was less accurate in predicting the EG location along the trajectory (seen earlier); thus, performance of the CTI model was considered poor.

In the SAP model, the false positive rate decreased from $7 \%$ to $0 \%$ and the false negative rate increased from $49 \%$ to $98 \%$ as $T_{\mathrm{SAP}}$ increased from 0.3 to 1.0 (table 3 ). Optimum false positive and false negative rates were difficult to obtain because the SAP model was used to locate the initiation point of EGs rather than the trajectories (discussed earlier). Hence, the performance of this model was also considered poor. In the WTI model, $T_{\mathrm{WTI}}$ of 6.8 and 9.8 could not predict the locations (i.e., all cells were identified as EG cells), resulting in no statistics being calculated; however, the model predicted locations using $T_{\mathrm{WTI}}=12.0$. The false positive rate was $34 \%$, and the false negative rate was $23 \%$ (table 3 ). The false positive and false negative rates were both near optimum, and increasing $T_{\text {WTI }}$ further may have improved the model predictions but was not pursued in this study.

The results show that the error matrix approach (occurrence analysis) produced a result similar to visual interpretation. The importance of the $T$ value in EG predictions was also well established. Further analysis to examine $T$ values using the SA model is presented below.

\section{LENGTH ANALYSIS}

Catchments in which both observed and predicted EGs were present were extracted and compared using NSE, $\mathrm{R}^{2}$, and PBIAS for all models and their corresponding $T$ values using $2 \mathrm{~m}$ DEM and field land use (table 4). The SA model with $T_{\mathrm{SA}}=5$ resulted in poor model agreement, whereas
Table 4. Coefficient of determination $\left(R^{2}\right)$, Nash-Sutcliffe efficiency (NSE), and percentage bias (PBIAS) for topographic index models (SA, CTI, SAP, and WTI) and their corresponding threshold (T) values in $\mathrm{S} 1$.

\begin{tabular}{ccccc}
\hline Threshold & SA & CTI & SAP & WTI \\
and Statistics & Model & Model & Model & Model \\
\hline Threshold & $T_{\mathrm{SA}}=5$ & $T_{\mathrm{CTI}}=12$ & $T_{\mathrm{SAP}}=0.3$ & - \\
$\mathrm{R}^{2}$ & 0.11 & 0.56 & 0.21 & - \\
NSE & -6.14 & -0.04 & 0.66 & - \\
PBIAS (\%) & -194.2 & -79.7 & 20.4 & - \\
\hline Threshold & $T_{\mathrm{SA}}=18$ & $T_{\mathrm{CTI}}=62$ & $T_{\mathrm{SAP}}=0.5$ & - \\
$\mathrm{R}^{2}$ & 0.58 & 0.45 & 0.15 & - \\
NSE & 0.66 & 0.48 & 0.53 & - \\
PBIAS (\%) & -41.4 & 60.2 & 54.5 & - \\
\hline Threshold & $T_{\mathrm{SA}}=40$ & $T_{\mathrm{CTI}}=100$ & $T_{\mathrm{SAP}}=1.0$ & $T_{\mathrm{WTI}}=12$ \\
$\mathrm{R}^{2}$ & 0.53 & 0.41 & 0.37 & 0.27 \\
NSE & 0.86 & 0.60 & 0.72 & -0.35 \\
PBIAS (\%) & 14.6 & 65.3 & 41.3 & -59.7 \\
\hline
\end{tabular}

$T_{\mathrm{SA}}=18$ and 40 resulted in very good agreement based on the $\mathrm{R}^{2}$, NSE, and PBIAS statistics (table 4). In the CTI model, $T_{\text {СTI }}=12$ resulted in poor model agreement, but $T_{\text {CTI }}$ $=62$ and 100 resulted in good agreement (table 4). An increase in $T$ value resulted in improved performance of both models. Model agreement for the SA model was better compared with the CTI model for higher $T$. The inclusion of plan curvature in the CTI model resulted in discontinuity and lower EG lengths (discussed earlier), which led to the observed reduction in agreement compared with the SA model.

For the SAP model, model agreements were good despite the poor results from occurrence statistics. This is because only catchments in which EGs (both predicted and observed) were present were considered for analysis, and the SAP model had very few catchments with EGs (both predicted and observed) present ( 103 for $T_{\mathrm{SAP}}=0.3$, 26 for $T_{\mathrm{SAP}}=0.5$, and 5 for $T_{\mathrm{SAP}}=1.0$ ). Thus, the statistics appeared better even though the SAP model was not capable of predicting location of EGs along the trajectory and had poor occurrence analysis results. Therefore, although the length statistics were better, overall model performance was considered poor. The WTI model with $T_{\mathrm{WTI}}=6.8$ and 12.8 did not yield results because no EGs were predicted at those thresholds, but $T_{\mathrm{WTI}}=12$ resulted in poor model agreement (table 4).

\section{SA MODEL ANALYSIS USING DIFFERENT THRESHOLDS}

Occurrence and length statistics revealed that $T$ values play a major role in predicting the occurrence and length of EGs. Further analysis of the SA model, which was the most promising from the above analyses, was used to explore response to varying $T$ values. The upper end of $T_{\mathrm{SA}}$ was expanded to 200 with eight individual values of $10,25,30$, $50,70,100,150$, and 200 added to cover the larger threshold range. Study area S1 was used for this analysis, and the results were verified in study area $\mathrm{S} 2$. For each $T$ value, the SA model was executed using $2 \mathrm{~m}$ DEM and field land use. Model performance was evaluated using the occurrence and length statistics procedures discussed earlier.

Figure 7 shows the false positive rate, false negative rate, and $\kappa$ statistic for each threshold $T$. In $\mathrm{S} 1$ (solid lines), the false positive rates decreased rapidly from $38 \%$ to $7 \%$ as $T_{\mathrm{SA}}$ increased from 10 to 50 and decreased gradually to $1 \%$ as 


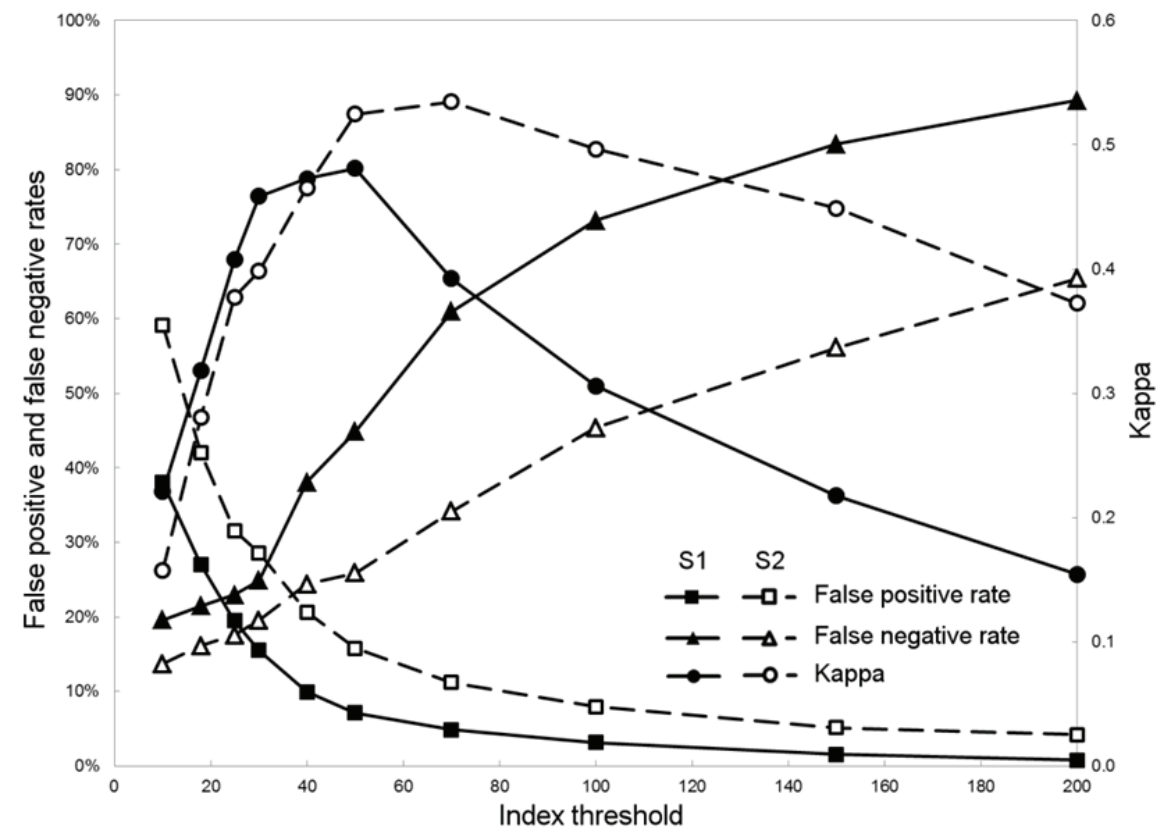

Figure 7. Occurrence statistics for SA model using $T_{\mathrm{SA}}$ values from 10 to 200 in $\mathrm{S} 1$ (solid lines) and S2 (dash lines).

$T_{\mathrm{SA}}$ increased from 50 to 200 . The false negative rates increased gradually from $20 \%$ to $25 \%$ as $T_{\mathrm{SA}}$ increased from 10 to 30 and increased rapidly from $25 \%$ to $89 \%$ as $T_{\mathrm{SA}}$ increased from 30 to 200 . The $\kappa$ increased rapidly from 0.22 to 0.46 as $T_{\mathrm{SA}}$ increased from 0 to 30 , attained a peak of 0.48 at $T_{\mathrm{SA}}=50$, and gradually decreased to 0.15 as $T_{\mathrm{SA}}$ increased to 200 .

The length statistics $\left(\mathrm{R}^{2}\right.$, NSE, and PBIAS) are presented in table 5 for all thresholds. In $\mathrm{S} 1$, as $T_{\mathrm{SA}}$ increased from its minimum value, $\mathrm{R}^{2}$ and NSE also increased, reaching maximum values at $T_{\mathrm{SA}}$ at $25\left(\mathrm{R}^{2}\right)$ and 30 (NSE), followed by a gradual decrease. PBIAS values were negative for small $T_{\mathrm{SA}}$ and positive for $T_{\mathrm{SA}}$ above 25 , with the best fit value at $T_{\mathrm{SA}}$ of 30 . All three statistics presented better results for the $T_{\mathrm{SA}}$ range from 25 to 40 (gray cells in table 5).

Increase in the $T_{\mathrm{SA}}$ value resulted in a decreased number of pixels meeting the $T_{\mathrm{SA}}$ value, resulting in reduced lengths predicted by the model. Because of this, the predicted number of EGs decreased, resulting in a lower number of catchments predicting the presence of EGs despite the presence of observed EGs, hence resulting in higher false negative rates. Increased $T_{\mathrm{SA}}$ (resulting in reduced length predicted by the model) also results in a lower number of catchments where predicted EGs are present, while observed EGs were absent, resulting in lower false positive rates.

In studies related to EGs, the $T_{\mathrm{SA}}$ thresholds that result in lower false positive and false negative rates while maintaining higher $\kappa$ and producing the best length comparison statistics better predict the occurrence and estimates length of EGs. In analyzing the statistics in figure 7 and table 5 , a $T_{\mathrm{SA}}$ of 30 produced near-optimal $\kappa$, the best NSE and PBIAS, and high $\mathrm{R}^{2}$ values (bold values in table 5) and is the best threshold value for EG identification in study area S1.

The SA model was verified in study area S2 using the procedures described above. The occurrence statistics are represented by dashed lines in figure 7 , while the length statistics are summarized in table 5. Model performance differed between the two study areas. In S2, the false positive rates were higher and false negative rates were lower for all $T_{\mathrm{SA}}$ values compared with $\mathrm{S} 1$. The false negative rate increased gradually, unlike in $\mathrm{S} 1$ where the false negative rate increased suddenly after $T_{\mathrm{SA}}=30$. At a $T_{\mathrm{SA}}$ of 200 , for example, $\kappa$ was 0.37 , the false negative rate was $67 \%$, and the false positive rate was $4 \%$ in $S 2$, compared with $\kappa$ of 0.15 , a false positive rate of $1 \%$, and a false negative rate of $89 \%$ in S1. This result shows that the SA model was able to predict the location of EGs along the main trajectory, even at higher $T_{\mathrm{SA}}$, better in $\mathrm{S} 2$ than in $\mathrm{S} 1$. Higher false positive rates in S2 were partially because EGs were identified along terrace channels. These EGs were not seen on the aerial images, and field investigation would be needed to verify their existence.

Table 5. Length statistics for SA model with $T_{\mathrm{SA}}$ values from 10 to 200 in $\mathrm{S1}$ and S2. Threshold ranges with better statistics are highlighted in gray, and statistics for the best performing threshold are printed in bold.

\begin{tabular}{|c|c|c|c|c|c|c|c|c|c|c|c|}
\hline \multirow[b]{2}{*}{ Study Area } & \multirow[b]{2}{*}{ Statistics } & \multicolumn{10}{|c|}{ Index Threshold $(T)$} \\
\hline & & 10 & 18 & 25 & 30 & 40 & 50 & 70 & 100 & 150 & 200 \\
\hline \multirow[t]{3}{*}{$\mathrm{S} 1$} & $\mathrm{R}^{2}$ & 0.56 & 0.58 & 0.62 & 0.58 & 0.53 & 0.42 & 0.36 & 0.43 & 0.52 & 0.41 \\
\hline & NSE & -0.75 & 0.66 & 0.83 & 0.86 & 0.86 & 0.80 & 0.72 & 0.78 & 0.76 & 0.67 \\
\hline & PBIAS (\%) & -110.8 & -41.4 & -13.8 & 5.3 & 14.6 & 23.4 & 37.6 & 29.3 & 34.7 & 43.9 \\
\hline \multirow[t]{3}{*}{ S2 } & $\mathrm{R}^{2}$ & 0.64 & 0.68 & 0.67 & 0.66 & 0.64 & 0.61 & 0.49 & 0.47 & 0.51 & 0.35 \\
\hline & NSE & 0.10 & 0.66 & 0.77 & 0.81 & 0.84 & 0.85 & 0.81 & 0.81 & 0.82 & 0.74 \\
\hline & PBIAS (\%) & -74.1 & -38.7 & -25.6 & -20.0 & -10.9 & -4.0 & 4.1 & 8.0 & 11.3 & 16.7 \\
\hline
\end{tabular}


Similar to the occurrence statistics, the length statistics showed better results for higher $T_{\mathrm{SA}}$ in $\mathrm{S} 2$ than in $\mathrm{S} 1$ (table 5). Values of $\mathrm{R}^{2}$ were above 0.6 for $T_{\mathrm{SA}}$ values from 10 to 50 , NSE peaked at $T_{\mathrm{SA}}$ of 40 and 50 , and PBIAS was closest to zero for $T_{\mathrm{SA}}$ of 50 and 70 . The optimum false positive and false negative rates with $\kappa$ close to peak were seen for $T_{\mathrm{SA}}$ of 40 and 50 . Considering all the statistics, a $T_{\mathrm{SA}}$ of 50 can be selected as the best threshold value for S2.

$T_{\mathrm{SA}}$ of 50 better predicted the occurrence and length of EGs in $\mathrm{S} 2$, whereas $T_{\mathrm{SA}}$ of 30 performed better in $\mathrm{S} 1$. Different critical thresholds in S1 and S2 were influenced by differences in slope distribution and catchment size in two areas. While average catchment size of agricultural fields where EGs were present in S1 was only 6\% (2.5 ha vs. 2.35 ha) larger than in S2, the average catchment slope was $41 \%$ higher in S1 than in S2. Both larger catchment size and steeper slopes in $\mathrm{S} 1$ contributed to longer EGs that required lower $T_{\mathrm{SA}}$ to be identified by the SA model. This finding, that the optimal $T_{\mathrm{SA}}$ differed between study areas separated by only $290 \mathrm{~km}$ (180 mi), may indicate that a given EG topographic index model needs to be calibrated to find the $T$ value for optimal EG occurrence and length simulation for a given location.

\section{Conclusions}

The performance of existing topographic index models (SA, CTI, SAP, and WTI) to predict EG locations was evaluated. Impacts of topographic model critical thresholds, DEM resolution, and land use data source were also evaluated. A methodology to derive length using the topographic index models was developed and evaluated.

Results of visual interpretation show that the SA model better predicted EG location and lengths than the other models. The SA and CTI model predictions had similar pattern in terms of locating EG trajectory, but the CTI model predictions had greater discontinuity along the trajectory. The method developed to derive length in this study was sensitive to discontinuity, so the CTI model performance was poor. Occurrence and length statistics also show that the SA model better predicted the occurrence and length of EGs than the other models. The SAP model performed poorly among all the models in predicting occurrence and lengths because this model was used to find EG initiation points. The WTI model was not able to predict the occurrence and lengths at $T_{\mathrm{WTI}}=6.8$ and 9.8 , but it improved prediction of location and lengths at $T_{\mathrm{WTI}}=12$. Further testing of the WTI model was not conducted.

Different threshold values were required by the SA model to best predict the occurrence and length of EGs in S1 (study area $1, T_{\mathrm{SA}}=30$ ) and $\mathrm{S} 2$ (study area $2, T_{\mathrm{SA}}=50$ ). The need for different thresholds among study regions indicated that other factors that vary among the regions influence EG occurrence and length prediction; therefore, individual calibration of the topographic index model threshold for each application site is needed.

Finer-resolution DEMs (e.g., $2 \mathrm{~m}$ ) are needed to better predict occurrence and length of EGs. Coarser-resolution DEMs (10 m or greater) cannot locate EGs but may be useful for locating larger classical gullies in agricultural fields or gullies in rangeland. When considering EGs only within agricultural fields, field land use is recommended over NASS land use because NASS land use results in either over- or underpredictions.

The EG locations predicted using these topographic index models were not accurate without calibration. Topographic features specific to a study area, such as average catchment size and slope, play an important role in EG identification. Future studies may apply scaling techniques to seek normalization of such topographic parameters, making the topographic index model approach independent of land area. Inclusion of other factors that vary by region or field, such as land management practices, precipitation characteristics, and soil properties, would likely improve EG model performance and may be useful in simulation of ephemeral gullies.

\section{ACKNOWLEDGEMENTS}

This material is based on work supported by the USDA National Institute of Food and Agriculture (NIFA) under Agreement No. 2005-51130-02364 and No. 2011-5113031128. Comments on the manuscript provided by three anonymous reviewers are greatly appreciated.

\section{REFERENCES}

Begin, Z. B., and S. A. Schumm. 1979. Instability of alluvial valley floors: A method for its assessment. Trans. ASAE 22(2): 347-350.

Bingner, R. L., and F. D. Theurer. 2003. AnnAGNPS technical processes documentation. Version 3.2. Oxford, Miss.: USDAARS National Sedimentation Laboratory.

Bussen, P. 2009. Analysis of a rapid soil erosion assessment tool. MS thesis. Manhattan, Kans.: Kansas State University, Department of Biological and Agricultural Engineering. Available at: https://krex.k-state.edu/dspace/handle/2097/2351.

Capra, A., L. M. Mazzara, and B. Scicolone. 2005. Application of the EGEM model to predict ephemeral gully erosion in Sicily (Italy). Catena 59(2): 133-146.

Capra, A., P. Porto, and B. Scicolone. 2009. Relationships between rainfall characteristics and ephemeral gully erosion in a cultivated catchment in Sicily (Italy). Soil Till. Res. 105(1): 77-87.

Chaubey, I., A. S. Cotter, T. A. Costello, and T. Soerens. 2005. Effect of DEM data resolution on SWAT output uncertainty. Hydrol. Proc. 19(3): 621-628.

Congalton, R. G. 1991. A review of assessing the accuracy of classifications of remotely sensed data. Remote Sensing Environ. 37(1): 35-46.

Daggupati, N. P. 2012. GIS methods to implement sediment best management practices and locate ephemeral gullies. $\mathrm{PhD}$ diss. Manhattan, Kans.: Kansas State University, Department of Biological and Agricultural Engineering. Available at: https://krex.k-state.edu/dspace/handle/2097/13522.

Daggupati, P., K. R. Douglas-Mankin, A. Y. Sheshukov, and P. L. Barnes. 2010. Monitoring and estimating ephemeral gully erosion using field measurements and GIS. ASABE Paper No. 1009663. St. Joseph, Mich.: ASABE.

Daggupati, P., K. R. Douglas-Mankin, A. Y. Sheshukov, P. L. Barnes, and D. L. Devlin. 2011. Field-level targeting using SWAT: Mapping output from HRUs to fields and assessing limitations of GIS input data. Trans. ASABE 54(2): 501-514.

Desmet, P. J. J., and G. Govers. 1997. Two-dimensional modelling of the within-field variation in rill and gully geometry and location related to topography. Catena 29(3-4): 283-306.

Desmet, P. J. J., J. Poesen, G. Govers, and K. Vandaele. 1999. Importance of slope gradient and contributing area for optimal 
prediction of the initiation and trajectory of ephemeral gullies. Catena 37(3-4): 377-392.

ESRI. 2011. ArcGIS Desktop: Release 10. Redlands, Cal.: Environmental Systems Research Institute.

Flanagan, D. C., and M. Nearing. 1995. Water Erosion Prediction Project: Hillslope profile and watershed model documentation. Report No. 10. West Lafayette, Ind.: USDA-ARS National Soil Erosion Research Laboratory.

Foster, G. R. 1986. Chapter 4: Understanding ephemeral gully erosion. In Soil Conservation: An Assessment of the National Resources Inventory, Vol. 2, 90-128. Washington, D.C.: National Academy Press.

Gordon, L. M., S. J. Bennett, R. L. Bingner, F. D. Theurer, and C. V. Alonso. 2007. Simulating ephemeral gully erosion in AnnAGNPS. Trans. ASABE 50(3): 857-866.

Grissinger, E. 1996a. Rill and gullies erosion. In Soil Erosion, Conservation, and Rehabilitation, 153-167. M. Agassi, ed. New York, N.Y.: Marcel Dekker.

Grissinger, E. 1996b. Reclamation of gullies and channel erosion. In Soil Erosion, Conservation, and Rehabilitation, 301-313. M. Agassi, ed. New York, N.Y.: Marcel Dekker.

Gutierrez, A. G., S. Schnabel, and A. M. Felicisimo. 2009. Modelling the occurrence of gullies in rangelands of southwest Spain. Earth Surf. Proc. Landforms 34(14): 1894-1902.

Hauge, C. 1977. Soil erosion definitions. California Geol. 30: 202203.

Holmes, K. W., O. A. Chadwick, and P. C. Kyriakidis. 2000. Error in a USGS 30-meter digital elevation model and its impact on terrain modeling. J. Hydrol. 233(1): 154-173.

Horton, R. E. 1945. Erosional development of streams and their drainage basins: Hydrophysical approach to quantitative morphology. Geol. Soc. America Bull. 56(3): 275-370.

Kim, I. J. 2007. Identifying the roles of overland flow characteristics and vegetated buffer systems for non-point source pollution control. PhD diss. Manhattan, Kans.: Kansas State University, Department of Biological and Agricultural Engineering.

Knapen, A., and J. Poesen. 2010. Soil erosion resistance effects on rill and gully initiation points and dimensions. Earth Surf. Proc. Landforms. 35(2): 217-228.

Knisel, W. G. 1980. CREAMS: A field-scale model for chemicals, runoff, and erosion from agricultural management systems. Conservation Research Report No. 26. Washington, D.C.: USDA Science and Education Administration.

Knisel, W. G. 1993. GLEAMS: Groundwater loading effects of agricultural management systems. Publication No. 5. Tifton, Ga.: University of Georgia, Coastal Plains Experiment Station.

Meyer, A., and J. A. Martinez-Casasnovas. 1999. Prediction of existing gully erosion in vineyard parcels of the NE Spain: A logistic modelling approach. Soil Tillage Res. 50(3-4): 319-333.

Momm, H. G., R. L. Bingner, R. Wells, and S. D. S. Dabney. 2011. Analysis of topographic attributes for identification of ephemeral gully channel initiation in agricultural watersheds. ASABE Paper No. 1111250. St. Joseph, Mich.: ASABE.

Montgomery, D. R. 2007. Dirt: Erosion of Civilizations. Berkeley, Cal.: University of California Press.

Moore, I. D., G. J. Burch, and D. H. Mackenzie. 1988. Topographic effects on the distribution of surface soil water and the location of ephemeral gullies. Trans. ASAE 31(4): 1098-1107.

Moore, I. D., R. B. Grayson, and A. R. Ladson. 1991. Digital terrain modelling: A review of hydrological, geomorphological, and biological applications. Hydrol. Proc. 5(1): 3-30.

Moriasi, D. N., J. G. Arnold, M. W. Van Liew, R. L. Bingner, R. D. Harmel, and T. L. Veith. 2007. Model evaluation guidelines for systematic quantification of accuracy in watershed simulations. Trans. ASABE 50(3): 885-900.

Nachtergaele, J., and J. Poesen. 1999. Assessment of soil losses by ephemeral gully erosion using high-altitude (stereo) aerial photographs. Earth Surf. Proc. Landforms 24(8): 693-706.

Nachtergaele, J., J. Poesen, L. Vandekerckhove, D. O. Wijdenes, and M. Roxo. 2001a. Testing the ephemeral gully erosion model (EGEM) for two Mediterranean environments. Earth Surf. Proc. Landforms 26(1): 17-30.

Nachtergaele, J., J. Poesen, and A. Steegen. 2001b. The value of a physically based model versus an empirical approach in the prediction of ephemeral gully erosion for loess-derived soils. Geomorphology 40(3-4): 237-252.

Parker, C., C. Thorne, R. Bingner, R. Wells, and D. Wilcox. 2007. Automated mapping of potential for ephemeral gully formation in agricultural watersheds laboratory. Publication No. 56. Oxford, Miss.: USDA-ARS National Sedimentation Laboratory.

Patton, P. C., and S. A. Schumm, 1975. Gully erosion, northwestern Colorado: A threshold phenomenon. Geology 3(2): 88-90.

Poesen, J. 1993. Gully typology and gully control measures in the European loess belt. In Farmland Erosion in Temperate Plains Environment and Hills, 221-239. S. Wicherek, ed. Amsterdam, The Netherlands: Elsevier.

Poesen, J., J. Boardman, B. Wilcox, and C. Valentin. 1996. Water erosion monitoring and experimentation for global change studies. J. Soil Water Cons. 51(5): 386-390.

Poesen, J., J. Nachtergaele, G. Verstraeten, and C. Valentin. 2003. Gully erosion and environmental change: Importance and research needs. Catena 50(2-4): 91-133.

Poesen, J., D. Torri, and T. Vanwalleghem. 2011. Chapter 19: Gully erosion: Procedures to adopt when modelling soil erosion in landscapes affected by gullying. In Handbook of Erosion Modelling, 360-386. R. P. C. Morgan and M. A. Nearing, eds. Oxford, U.K.: Blackwell-Wiley.

Smith, L. 1993. Investigation of ephemeral gullies in loessial soils in Mississippi. Technical Report GL-93-11. Vicksburg, Miss.: U.S. Army Corps of Engineers, Waterways Experiment Station.

Souchere, V., O. Cerdan, and B. Ludwig. 2003. Modeling ephemeral gully erosion in small cultivated catchments. Catena 50(2-4): 489505.

SSSA. 2008. Glossary of soil science terms. Madison, Wisc.: Soil Science Society of America, Soil Science Glossary Terms Committee. Available at: https://www.soils.org/publications/soilsglossary.

Thorne, C. R., and L. W. Zevenbergen. 1984. On-site prediction of ephemeral gully erosion. Report to the USDA Agricultural Research and Soil Conservation Services.

Thorne, C. R., L. W. Zevenbergen, E. H. Grissinger, and J. B. Murphey. 1986. Ephemeral gullies as sources of sediment. In Proc. 4th Federal Interagency Sed. Conf., 3.152-3.161. Reston, Va.: U.S. Geological Survey.

Vandaele, K., J. Poesen, G. Govers, and B. van Wesemael. 1996a. Geomorphic threshold conditions for ephemeral gully incision. Geomorphology 16(2): 161-173.

Vandaele, K., J. Poesen, J. R. Marques da Silva, and P. Desmet. 1996b. Rates and predictability of ephemeral gully erosion in two contrasting environments. Geomorphologie: Relief, Proc., Environ. 2(2): 83-96.

Vandekerckhove, L., J. Poesen, D. Oostwoud Wijdenes, and T. de Figueiredo. 1998. Topographical thresholds for ephemeral gully initiation in intensively cultivated areas of the Mediterranean. Catena 33(3-4): 271-292.

Vandekerckhove, L., J. Poesen, and D. O. Wijdenes. 2000. Thresholds for gully initiation and sedimentation in Mediterranean Europe. Earth Surf. Proc. Landforms 25(11): 1201-1220.

Woodward, D. E. 1999. Method to predict cropland ephemeral gully erosion. Catena 37(3-4): 393-399.

Zevenbergen, L. W., and C. R. Thorne. 1987. Quantitative analysis of land surface topography. Earth Surf. Proc. Landforms 12(1): 47-56. 